\title{
Peningkatan Hasil Belajar Siswa melalui Model Pembelajaran Problem Based Learning (PBL) pada Mata Pelajaran IPA Kelas IV SDN Blimbing Kabupaten Kediri
}

\author{
Diterima: \\ 5 Juni 2021 \\ Revisi: \\ 26 Juli 2021 \\ Terbit:
}

1 Februari 2022

\author{
Indra Sulistiana \\ SDN Blimbing Gurah \\ Kediri, Indonesia \\ E-mail: indrasulistiana@gmail.com
}

\begin{abstract}
Abstrak - Penelitian ini disusun dengan tujuan untuk meningkatkan hasil belajar siswa pada mata pelajaran IPA menggunakan model pembelajaran problem based learning pada peserta didik kelas IV SDN Blimbing, Kec. Gurah, Kab.Kediri. Berdasarkan temuan peneliti terkait pembelajaran jarak jauh yang sekarang sedang dijalani di sekolah-sekolah di Indonesia karena pandemi Covid-19 membuat hasil belajar siswa di SDN Blimbing menurun. Hal ini dapat dilihat dari hasil penilaian yang dilakukan oleh guru. Hanya 25\% siswa SDN Blimbing Kelas IV yang mampu memenuhi KKM, sedangkan 75\% siswa lainnya belum mampu memenuhi KKM yang telah ditentukan. Dengan menggunakan model pembelajaran Problem Based Learning membuat siswa belajar untuk menghadapi masalah pada dunia nyata untuk memulai pembelajaran. Sebelum siswa mempelajari konsep/materi, siswa akan diberikan sebuah masalah yang harus dipecahkan. Oleh karena itu, untuk memecahkan masalah tersebut siswa akan memiliki kesadaran terhadap kebutuhan pengetahuan baru yang harus dipelajari untuk memecahkan masalah yang diberikan. Berdasarkan hasil penelitian yang dilakukan, dapat disimpulkan bahwa dengan menggunakan model pembelajaran Problem Based Learning dapat meningkatkan hasil belajar siswa kelas IV SDN Blimbing Kab. Kediri. Hal ini dapat dilihat dari prosentasi ketuntasan pada siklus I sebesar $60 \%$ meningkat menjadi $85 \%$ pada siklus II. Berdasarkan kesimpulan tersebut, saran yang dapat disampaikan adalah sebaiknya guru mencari metode yang tepat sesuai dengan materi yang akan diajarkan kepada siswa. Guru hendaknya selalu melakukan refleksi setelah melakukan proses pembelajaran.
\end{abstract}

Kata Kunci - hasil belajar, model Problem Based Learning (PBL), IPA

\begin{abstract}
This study was structured with the aim of improving student learning outcomes in science subjects using a problem based learning model for fourth grade students at SDN Blimbing, Kec. Gurah, $K a b$. Kediri. Based on the findings of researchers related to distance learning that is currently being carried out in schools in Indonesia because the Covid-19 pandemic has made student learning outcomes at SDN Blimbing decline. This can be seen from the results of the assessment conducted by the teacher. Only 25\% of students of SDN Blimbing Class IV are able to fulfill the KKM, while the other $75 \%$ of students have not been able to meet the KKM that has been determined. By using the Problem Based Learning learning model, students learn to face problems in the real world to start learning. Before students learn the concept/material, students will be given a problem to solve. Therefore, to solve these problems students will have an awareness of the need for new knowledge that must be learned to solve a given problem. Based on the results of the research conducted, it can be concluded that using the Problem Based Learning learning model can improve the learning outcomes of fourth grade students at SDN Blimbing Kab. Kediri. This can be seen from the percentage of completeness in the first cycle of $60 \%$ increased to $85 \%$ in the second cycle. Based on these conclusions, the suggestion that can be conveyed is that the teacher should look for the right method according to the material to be taught to students. Teachers should always reflect after the learning process.
\end{abstract}

Keywords - learning outcomes, Problem Based Learning (PBL) model, IPA 
PTK, Vol.2 No.2 2022

ISSN: 2747-1977 (Print) / 2747-1969 (Online)

DOI: https://doi.org/10.53624/ptk.v2i2.50

\section{PENDAHULUAN}

Dalam rangka mencerdaskan kehidupan bangsa salah satu upaya yang dapat dilakukan adalah melalui pendidikan. Bidang pendidikan merupakan salah satu faktor penting guna mempersiapkan generasi yang mampu bersaing di abad 21 ini. Pendidik dalam duia pendidikan diharapkan mampu mengantarkan anak-anak bangsa untuk menjadi generasi yang cerdas dan mampu menghadapi persaingan dalam dunia ke depannya.Proses pendidikan yang berkualitas tidak hanya mengantarkan siswa cerdas dalam bidang pengetahuan saja, akan tetapi diharapkan siswa juga cerdas dalam akhlak dan karakternya. Dalam UU No. 20 tahun 2003 tentang Sistem Pendidikan Nasional, pengembangan kurikulum dilakukan dengan mengacu pada standar nasional pendidikan untuk mewujudkan tujuan pendidikan nasional. Kurikulum pada semua jenjang dan jenis pendidikan dikembangkan dengan prinsip diversifikasi sesuai dengan satuan pendidikan, potensi daerah, dan peserta didik.

Selain itu Pemerintah juga mengatur tentang sistem penilaian yaitu pada Permendikbud No. 23 tahun 2016, kriteria ketuntasan minimal yang selanjutnya disebut KKM adalah kriteria ketuntasan belajar yang ditentukan oleh satuan pendidikan yang mengacu pada standar kompetensi kelulusan, dengan mempertimbangkan karateristik peserta didik, karakteristik mata pelajaran, dan kondisi satuan pendidikan. Di sini, peserta didik diharapkan mampu memenuhi KKM yang telah ditetapkan oleh satuan pendidikan. Pendidikan harus direncanakan secara matang agar semua pihak yang terlibat yaitu siswa dan pendidik terlibat dengan baik. Tidak hanya pendidik saja yang berperan aktif dalam proses pembelajaran tetapi siswa juga diharapkan aktif dalam kegiatan pembelajaran. Keaktifan siswa dalam proses pembelajaran diperlukan agar komunikasi tidak hanya satu arah, dan pembelajaran tidak hanya didominasi oleh guru yang aktif ceramah. Pembelajaran yang membuat siswa aktif terlibat akan membuat pembelajaran menjadi lebih bermakna, siswa tidak akan bosan dengan proses pembelajaran tetapi siswa akan terlihat antusias mengikuti pelajaran karena siswa terlibat langsung dalam mencari pengetahuannya (Susanto 2016).

Berdasarkan hasil refleksi peneliti pada pembelajaran IPA materi bentuk energi dan perubahannya hasil pembelajaran siswa hanya 25 siswa yang berhasil mencapai KKM. Hal ini disebabkan oleh beberapa faktor yaitu, pembelajaran dilaksanakan secara daring, metode guru yang digunakan kurang bervariasi, tidak ada media yang menarik perhatian siswa untuk lebih semangat belajar. Peran siswa dalam proses pembelajaran juga terlihat kurang aktif,hal ini terlihat dari siswa malas dalam mejawab pertanyaan yang diajukan oleh guru dan siswa juga 
tidak ada yang bertanya kepada guru terkait materi yang belum dipahami. Siswa masih cenderung malas dalam menggali kemampuan berpikirnya dalam proses pembelajaran.

Berdasarkan permasalahan-permasalahan di atas maka perlu adanya peningkatan kualitas pembelajaran agar hasil belajar siswa dapat meningkat dan memenhi KKM. Salah satunya dengan mengembangkan model pembelajaran yang sudah ada. Kemendikbud melalui direktorat PSMP tahun 2008 mendefinisikan pembelajaran kontekstual sebagai suatu proses pendidikan yang bertujuan untuk memotivasi siswa untuk memahami makna materi pembelajaran dengan mengkaitkannya pada kehidupan sehari-hari (konteks pribadi, sosial, dan kultural) sehingga siswa memiliki pengetahuan/ketrampilan yang secara fleksibel dapat diterapkan dari suatu permasalahan/konteks ke permasalahan lain. Salah satu model pembelajaran kontekstual yang dapat diterapkan untuk anak-anak adalah model pembelajaran Problem Based Learning.

Problem Based Learning (PBL) merupakan model kurikulum yang berhubugan dengan masalah dunia nyata siswa. Masalah yang diseleksi mempunyai dua karakteristik penting, pertama masalah harus autentik yang berhubungan dengan kontek sosial siswa, kedua masalah harus berakar pada materi subjek dari kurikulum”. Terdapat tiga ciri utama dari model Problem Based Learning (PBL). Pertama, Problem Based Learning (PBL) merupakan rangkaian aktivitas pembelajaran, artinya dalam implementasi Problem Based Learning (PBL) ada sejumlah kegiatan yang harus dilakukan siswa, siswa tidak hanya mendengar, mencatat, kemudian menghafal materi pelajaran, tetapi melalui model problem based learning (PBL) siswa menjadi aktif berpikir, berkomunikasi, mencari dan mengolah data, dan akhirnya membuat kesimpulan. Kedua, aktivitas pembelajaran diarahkan untuk menyelesaikan masalah. Problem Based Learning (PBL) ini menempatkan masalah sebagai kata kunci dari proses pembelajaran. Artinya tanpa masalah pembelajaran tidak akan mungkin bisa berlangsung. Ketiga, pemecahan masalah menggunakan pendekatan berpikir secara ilmiah.

Menurut Nurhadi (2004) "Problem based learning adalah kegiatan interaksi antara stimulus dan respons, merupakan hubungan antara dua arah belajar dan lingkungan". Lingkungan memberi masukan kepada siswa berupa bantuan dan masalah, sedangkan sistem saraf otak berfungsi menafsirkan bantuan itu secara efektif sehingga yang dihadapi dapat diselidiki, dinilai, dianalisis, serta dicari pemecahannya dengan baik. PBL merupakan sebuah pendekatan pembelajaran yang menyajikan masalah konstektual sehingga merangsang siswa untuk belajar. Pada model pembelajaran Problem Based Learning (PBL), siswa akan dibentuk dalam suatu kelompok-kelompok kecil dan dalam kelompok-kelompok kecil tersebut siswa akan saling bekerja sama untuk memecahkan suatu masalah yang telah disepakati oleh siswa dan guru yang berkaitan dengan materi pelajaran. 
PTK, Vol.2 No.2 2022

ISSN: 2747-1977 (Print) / 2747-1969 (Online)

DOI: https://doi.org/10.53624/ptk.v2i2.50

Dari penelitian terdahulu, penggunaan model pembelajaran Problem Based Learning dapat membuat siswa aktif berdiskusi dengan kelompokan untuk memecahkan permasalahan dan menemukan konsepnya sendiri (Hajar 2016; Fauziah 2016). Berdasarkan pertimbangan tersebut, peneliti menyusun sebuah penelitian tindakan kelas dengan judul "Peningkatan Hasil Belajar Siswa Melalui Model Pembelajaran Problem Based Learning (PBL) Pada Mata Pelajaran IPA Materi Bentuk Energi dan Perubahan Bentuk Energi Kelas IV SDN Blimbing Kecamatan Gurah Kabupaten Kediri”. Berdasarkan judul tersebut dirumuskan tujuan penelitian tindakan ini adalah untuk meningkatkan hasil belajar siswa melalui model pembelajaran Problem Based Learning (PBL) pada mata pelajaran IPA materi bentuk energi dan perubahan bentuk energi pada siswa kelas IV SDN Blimbing Kecamatan Gurah Kabupaten Kediri.

\section{METODE}

\section{A. Metode Penelitian}

Metode Penelitian yang digunakan ini adalah Penelitian Tindakan Kelas (PTK). Penelitian tindakan kelas adalah penelitian yang dilakukan pendidik di dalam kelasnya sendiri melalui kegiatan refleksi diri (Dwitagama et al. 2010). Tujuan dari penelitian tindakan kelas ini untuk memperbaiki kinerjanya sebagai pendidik, sehingga hasil belajar peserta didik di dalam kelasnya menjadi meningkat dan secara sistem, mutu pendidikan juga meningkat. Penelitian ini dilaksanakan dengan rancangan model siklus PTK yang berulang, tahapannya terdiri dari perancangan, tindakan, observasi, refleksi. Penelitian ini dilaksanakan dalam 2 siklus, siklus pertama dengan materi perubahan bentuk energi dan pemanfaatannya, dan materi pada siklus kedua adalah energi dan perubahannya.

Sebelum Siklus I, Peneliti melakukan identifikasi masalah (analisis masalah, rumusan masalah, rencana perbaikan). Kemudian dilaksanakan siklus I yang meliputi: Perancangan, tindakan, observasi, refleksi. Berikut penjelasan masing-masing tahapannya. Perancangan, pada tahap ini peneliti mempersiapkan perangkat pembelajaran yang terdiri dari pengembangan RPP, penyiapan media video pembelajaran tentang bentuk energi dan bentuk perubahannya, LKPD, soal evaluasi dan lembar observasi pelaksanaan pembelajaran. Tindakan, pada tahap ini peneliti melaksanakan pembelajaran secara daring pada materi perubahan bentuk energi dan pemanfaatannya sesuai dengan perangkat yang disusun. Observasi, pada tahap ini, peneliti melakukan pengamatan jarak jauh proses pengerjaan lembar kerja oleh siswa melalui foto-foto saat siswa belajar dari rumah. Refleksi, pada tahap ini peneliti mencatat semua temuan selama proses dan setelah pembelajaran daring selesai. Pada tahap ini, juga dilakukan analisa hasil observasi, apa yang sudah dan belum tercapai pada siklus I untuk dilakukan perbaikan pada 
siklus berikutnya. Siklus II, pada tahap siklus II ini memiliki tahapan yang sama dengan siklus I yaitu perancangan, tindakan, observasi dan refleksi. Apa yang belum tercapai dalam siklus I bisa diteruskan pada siklus II ini. Kegiatan pada siklus ini menyesuaikan dengan permasalahan pembelajaran pada siklus I. Setelah siklus II berakhir makan penelitian ini dihentikan.

\section{B. Subjek Penelitian}

Subjek penelitian ini adalah siswa kelas IV SDN Blimbing Kecamatan Gurah Kabuaten Kediri tahun pelajaran 2019/2020. Jumlah siswa 20 anak yang terdiri dari 10 siswa laki-laki dan 10 siswa perempuan dengan kemampuan yang berbeda.

\section{Waktu Pelaksanaan}

Waktu pelaksanaan disesuaikan dengan jadwal di SDN Blimbing, yaitu tanggal 13 Maret 2020 sampai tanggal 20 Maret 2020 semester genap tahun pelajaran 2019/2020.

D. Data yang di analisis dalam penelitian ini adalah sebagai berikut.

Pengolahan hasil belajar siswa dianalisis untuk mengetahui peningkatan hasil belajar siswa dalam setiap siklusnya. Kemudian ketercapaian pelaksanaan penerapan model Problem Based Learning, dianalisis sesuai dengan hasil observasi selama proses pembelajaran.

\section{HASIL DAN PEMBAHASAN}

Tabel 1. Hasil Belajar Siswa pada materi Bentuk Energi dan Perubahan Bentuk Energi

\begin{tabular}{ccccc}
\hline \multirow{2}{*}{ No } & Nama (Inisial) & Pra Tindakan & Skor Evaluasi Siklus & Skor Evaluasi Siklus \\
& II & 30 & 50 & II \\
\hline 1 & RPP & 40 & 60 & 80 \\
\hline 2 & VPP & 30 & 50 & 80 \\
\hline 3 & YFD & 35 & 55 & 78 \\
\hline 4 & AFK & 50 & 78 & 85 \\
\hline 5 & AIA & 55 & 80 & 90 \\
\hline 6 & AS & 60 & 80 & 90 \\
\hline 7 & ARS & 45 & 78 & 85 \\
\hline 8 & AR & 40 & 55 & 80 \\
\hline 9 & ASD & 55 & 78 & 90 \\
\hline 10 & CK & 76 & 85 & 100 \\
\hline 11 & DYA & 60 & 78 & 85 \\
\hline 12 & DJDS & 78 & 85 & 65 \\
\hline 13 & DRR & 40 & 55 & 95 \\
\hline 14 & FDP & 78 & 85 & 95 \\
\hline 15 & FNS & 78 & 85 & 65 \\
\hline 16 & HKPA & 40 & 55 & 100 \\
\hline 17 & NKDR & 80 & 85 & 60 \\
\hline 18 & NKF & 40 & 55 & 90 \\
\hline 19 & RPR & 45 & 78 & 1693 \\
\hline 20 & Jumlah & 1055 & 7410 & 84,65 \\
\hline & Rata-Rata & 52,75 & $60 \%$ & $85 \%$ \\
\hline & $25 \%$ & & \\
\hline
\end{tabular}

PTK: Jurnal Tindakan Kelas | Hal:127-133 
PTK, Vol.2 No.2 2022

ISSN: 2747-1977 (Print) / 2747-1969 (Online)

DOI: https://doi.org/10.53624/ptk.v2i2.50

Gambar 1. Prosentase Ketuntasan Hasil Belajar Siswa

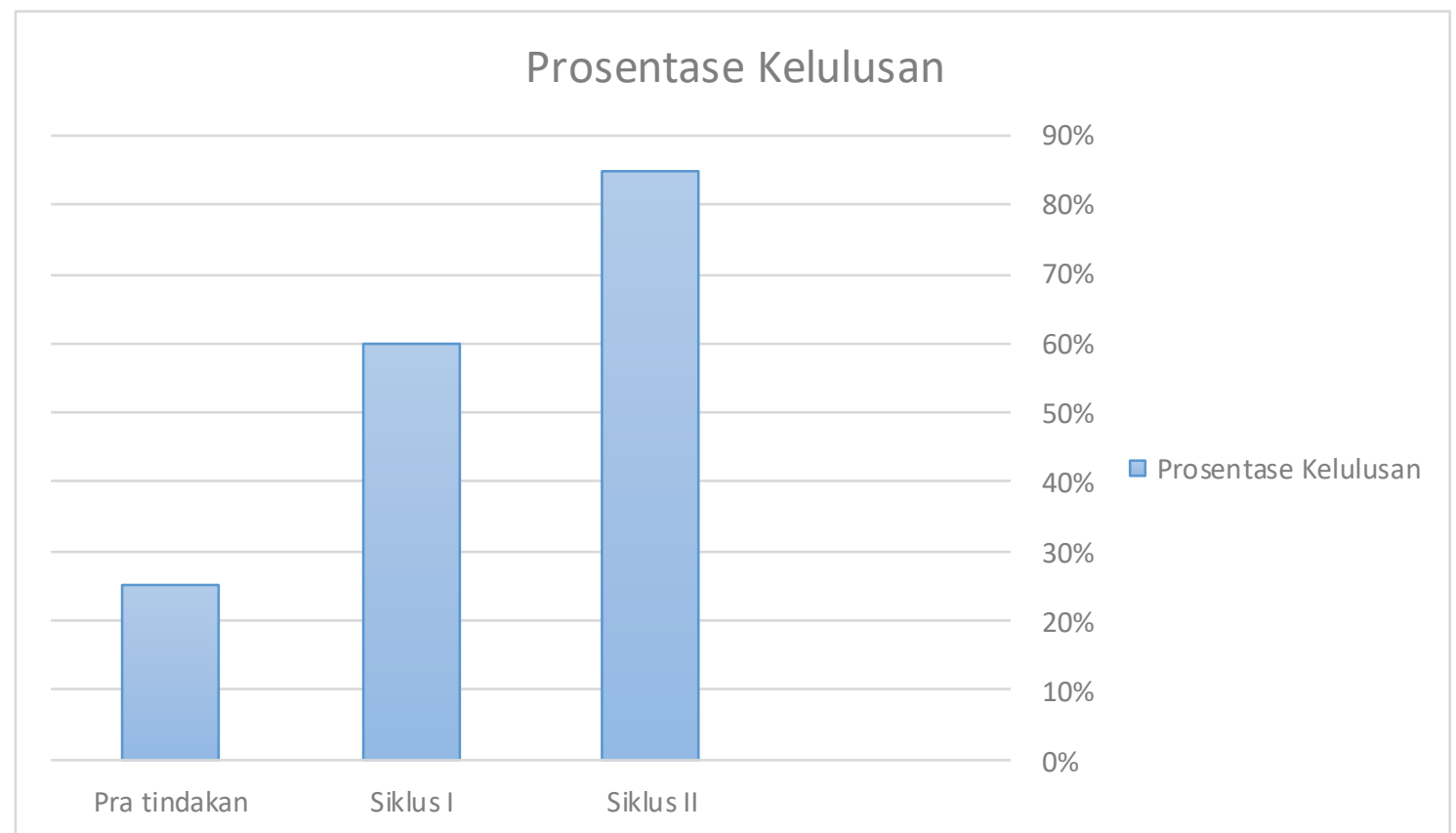

Berdasarkan hasil analisa yang disajikan pada gambar 1 bahwa pada siklus I Prosentase ketuntasan hasil belajar siswa pada muatan pelajaran IPA materi bentuk energi dan perubahan bentuk energi hanya $60 \%$ dari target $70 \%$. Dari 20 siswa, hanya 12 siswa yang tuntas dalam evaluasi hasil belajar. Hal tersebut terjadi karena siswa kurang antusias dalam mengikuti pembelajaran. Siswa juga mengalami kesulitan dalam mengunduh video pembelajaran. Belum adanya koordinasi jam dimulainya pembelajaran, mengakibatkan banyak siswa yang terlambat mengikuti kegiatan pembelajaran. Guru yang terkesan buru-buru dalam pembelajaran, menyebabkan siswa kurang memahami materi yang disampaikan.

Setelah dilaksanakan perbaikan pembelajaran pada Siklus II, terlihat peningkatan pada prosentase ketuntasan hasil belajar siswa, yaitu 85\%. Dari 20 siswa hanya 3 siswa yang belum memenuhi KKM. Hal itu membuktikan bahwa Model pembelajaran Problem Based Learning (PBL) mampu meningkatkan hasil belajar siswa kelas IV di SDN Blimbing, Kabupaten Kediri. Dengan demikian target sudah terpenuhi yaitu di atas $70 \%$ hasil ketuntasan siswa. 


\section{KESIMPULAN}

Berdasarkan hasil penelitian yang telah dilakukan, dapat ditarik kesimpulan bahwa Model Pembelajaran Problem Based Learning (PBL) mampu meningkatkan hasil belajar siswa kelas IV SDN Blimbing Kabupaten Kediri tahun pelajaran 2019/ 2020. Langkah-langkah pembelajaran dengan model Problem Based Learning (PBL) mampu meningkatkan antusias belajar siswa kelas IV SDN Blimbing Kabupaten Kediri tahun pelajaran 2019/ 2020 sehingga, jika pada pembelajaran siklus I ketuntasan belajar hanya mencapai $60 \%$ berhasil meningkat menjadi $85 \%$ pada pembelajaran siklus II. Berdasarkan paparan data, temuan penelitian dan pembahasan maka dapat dikemukakan saran atas kekurangan yang muncul dalam pelaksanaan penelitian agar menjadi bahan perbaikan bagi peneliti, peneliti lain, atau guru. Guru sebaiknya mencari metode yang tepat sesuai materi yang akan diajarkan kepada siswa. Penerapan model pembelajaran Problem Based Learning (PBL) dapat dipertimbangkan sebagai salah satu pendekatan pembelajaran yang dapat diterapkan di kelas karema dapat meningkatkan kualitas pembelajaran yang dibuktikan dengan meningkatnya hasil belajar siswa. Guru hendaknya selalu melakukan refleksi pada akhir pembelajaran agar bisa memperbaiki kualitas pembelajaran pada pertemuan berikutnya.

\section{DAFTAR PUSTAKA}

Dwitagama, et al. 2010. Mengenal Penelitian Tindakan Kelas. Jakarta: PT Indeks.

Fauziah, Delia. 2016. Penerapan Model Problem Based Learning Untuk Meningkatkan Hasil Belajar Siswa Pada Pembelajaran IPS di Sekolah Dasar. Jurnal Pendidikan Guru Sekolah Dasar, Vol. I No. I. Hal 104-105.

Hajar, 'A Nisaul, dkk. 2016. Penerapan Model Pembelajaran Problem Based Learning (PBL) Untuk Meningkatkan Hasil Belajar Siswa Kelas X-3 Pada Mata Pelajaran Sosiologi SMA Negeri Kebakkramat Tahun Ajaran 2015/2016. Universitas Sebelas Maret.

Nurhadi, 2004. Pembelajaran Kontekstual dan penerapannya dalam KBK. Malang: UM Press Permendikbud Nomor 23 tahun 2016. Kriteria Ketuntasan Minimum. Jakarta: Depdikbud. Susanto, Ahmad. 2016. Teori Belajar Dan Pembelajaran Di Sekolah Dasar. Kencana. Undang-undang nomor 20 tahun 2003. Sistem Pendidikan Nasional. Jakarta: Kemendiknas. 